\title{
A Case of Pseudopheochromocytoma Associated with Clozapine Therapy
}

\author{
Dilek Arpaci ${ }^{1^{*}}$, Aysel Gurkan Tocoglu², Yasemin Gunduz ${ }^{3}$, Sumeyye Korkmaz ${ }^{2}$, Lacin Tatli ${ }^{3}$, Baris Isiloglu ${ }^{4}$ and Ali Tamer ${ }^{2}$ \\ ${ }^{1}$ Sakarya University Education and Research Hospital, Department of Endocrinology, Sakarya, Turkey \\ ${ }^{2}$ Sakarya University Education and Research Hospital, Department of Internal Medicine, Sakarya, Turkey \\ ${ }^{3}$ Sakarya University Education and Research Hospital, Department of Radiology, Sakarya, Turkey \\ ${ }^{4}$ Sakarya University Education and Research Hospital, Department of Psychiatry, Sakarya, Turkey
}

*Corresponding author: Dilek Arpaci, Sakarya University Education and Research Hospital, Sakarya, Turkey; Tel: 902642550865; E-mail: drarpaci@gmail.com Received date: July 6, 2014, Accepted date: September 1, 2014, Published date: September 10, 2014

Copyright: (c) 2014 Dilek Arpaci, et al., This is an open-access article distributed under the terms of the Creative Commons Attribution License, which permits unrestricted use, distribution, and reproduction in any medium, provided the original author and source are credited.

\begin{abstract}
Background: An elevated plasma noradrenaline level is a consistent clinical effect of clozapine, which is due to its potent effect on $\alpha 2$-adrenergic receptors. Clozapine, a tricyclic dibenzodiazepine derivative, is used to treat refractory schizophrenia. In this report we present a case of pseudopheochromocytoma in a schizophrenic patient treated with clozapine.
\end{abstract}

Case: A 55-year-old female diagnosed with schizophrenia referred from psychiatry clinic to endocrinology clinic detected with bilateral adrenal masses. She was hypertensive and she used nifedipine. Urine catecholamines, especially normetanephrine, were extremely elevated; however, she did not have any pheochromocytoma-related symptoms. Adrenal imaging was not compatible with pheochromocytoma. Following psychiatric consultation, clozapine was withdrawn for 1 week, and then 24-h urine catecholamineswere normal. Metaiodobenzylguanidine (MIBG) scan was normal.

Conclusion: Given the potentially significant morbidity associated with paranoid schizophrenia, especially in undiagnosed cases, we recommend timely urinary catecholamine screening in patients that develop hypertension or other typical symptoms following the use of clozapine.

Keywords: Noradrenaline; Clozapine; Adrenal; Catecholamine

\section{Introduction}

Pheochromocytomas [Pheos] are catecholamine-producing tumors derived from chromaffin cells of the adrenal medulla or extra-adrenal paraganglia, of which $95 \%$ exist in the adrenal glands. Clinical manifestations arise as a result of their excessive production of catecholamines.

The symptoms of Pheos include sustained or paroxysmal hypertension, palpitations, headache, sweating, anxiety attacks, weight loss, and hyperglycemia. The clinical presentation of Pheos varies from incidental adrenal adenomas to life-threatening hypertensive crises [1].

The prevalence of Pheos in patients with adrenal incidentalomas is $0.3 \%-5 \%$ [2] however; the most critical reported issue related to adrenalincidentalomasis that the diagnosis of Pheos must be rule out. The recommended initial biochemical investigation for Pheos is measurement of plasma or urine metanephrines and normetanephrines. A level $>4$-fold urine level of catecholamines [ULC] indicates that Pheos is highly probable [3]. The 24-h metanephrine level (metanephrines and normetanephrines) is the most sensitive test for diagnosing Pheos. Negative test results exclude functional Pheos, except for dopamine-secreting Pheos or small tumors [4,5]. Radiologically Pheos appear circumscribed, and non homogeneous with cystic and hemorrhagic changes, based on CT scanning. The unenhanced attenuation value of Pheos on CT is usually
$>30 \mathrm{HU}$. On the other hand, they exhibit high signal intensity on T2weighted MRI. All of them are not specific for Pheos [6,7].

False positive Pheos test results may cause patient anxiety, leading to unnecessary imaging studies. False positive results for Pheos are due to physiological variations, laboratory errors, and drug interference $[8,9]$. Drug-related false positive elevations of ULC have been reported, and tricyclic antidepressants are among most common causes of false positive elevations of ULC [8,10,11]. Others medications reported to cause false-positive serum or urine studies are acetaminophen, phenoxybenzamine, amitriptyline, labetalol, haloperidol, levodopa, tamsulosin, venlafaxine, hydrochlorothiazide, and buspirone [12]. Selective serotonin re-uptake inhibitors [SSRIs] have been associated with false positive upper limits of normal [1].

Clozapine, a tricyclic dibenzodiazepine derivative, has an established role in the treatment of refractory schizophrenia. The literature includes a few case reports of a pseudopheochromocytoma syndrome associated with clozapine treatment. Elevation of the plasma noradrenaline level has been reported as a consistent clinical effect of clozapine, which is due to its potent effect on $\alpha 2$-adrenergic receptors [1-3]. Paradoxical hypertension with an elevated concentration of urinary catecholamines has also been reported in association with clozapine treatment, although rarely, and in association with other antipsychotic medications [13]. Here we present a patient with paranoid schizophrenia that was treated with clozapine and developed laboratory mimicking pheochromocytoma. 
Citation: Arpaci D, Tocoglu GA, Gunduz Y, Korkmaz S, Tatli L, et al. (2014) A Case of Pseudopheochromocytoma Associated with Clozapine Therapy. J Psychiatry 17: 1000138. doi:10.4172/2378-5756.1000138

Page 2 of 4

\section{Case Report}

A 55-year-old female diagnosed with paranoid schizophrenia, recurrent depressive illness, and generalized anxiety disorder based on ICD-10 criteria presented to Sakarya University Training and Research Hospital, Department of Endocrinology with bilateral adrenal masses. She had a history of hypertension and hyperlipidemia.

She used nifedipine for hypertension, atorvastatin for hyperlipidemia, and clozapine for schizophrenia. Size of her adrenal masses in the righta drenal $12 \times 22 \mathrm{~mm}$ and int he left adrenal gland were $38 \times 26 \mathrm{~mm}$, respectively.

Physical examination of the patient showed a height of $150 \mathrm{~cm}$, weight of $94 \mathrm{~kg}$, BMI of $42 \mathrm{~kg} \mathrm{~m}^{-2}$, and centralobesity, and absence of plethora, purple striae, buffalo hump, and hirsutism. Laboratory findings were as follows: sedimentation rate: $25 \mathrm{~mm} / \mathrm{h}$; C-reactive protein: $3.38 \mathrm{mg} / \mathrm{dL}$; fasting glucose: $88 \mathrm{mg} / \mathrm{dL}$; serum creatinine: 0.8 $\mathrm{mg} / \mathrm{dL}$; serum calcium: $9.2 \mathrm{mg} / \mathrm{dL}$ : albumin: $3.7 \mathrm{~g} / \mathrm{dL}$; serum sodium: $140 \mathrm{mg} / \mathrm{dL}$; serum potassium: $4.7 \mathrm{mg} / \mathrm{dL}$. Complete blood count was normal. The basal cortisol level was $25 \mu \mathrm{g} / \mathrm{dL}$, overnight (23000) cortisol was $3.1 \mu \mathrm{g} / \mathrm{dL}$, early morning serum cortisol level was $18 \mu \mathrm{g} / \mathrm{dL}$, and ACTH (adrenocorticotropic hormone) was $15 \mathrm{pg} / \mathrm{dL}$. The $24-\mathrm{h}$ urine cortisol level was $47 \mu \mathrm{g} / \mathrm{d}$. The after overnight $1-\mathrm{mg}$ dexamethasone suppression test [LDDST (low-dose dexamethasone suppression test)] cortisol level was $5.5 \mu \mathrm{g} / \mathrm{dL} ; 2 \mathrm{~d}$ later the $2-\mathrm{mg}$ dexamethasone suppression test cortisol level was $1.8 \mu \mathrm{g} / \mathrm{dL}$. Basal dehydro epiandrosterone sulphate (DHEAS) level was normal. As the patient's cortisoldiurnalrhythm was intact and she didn't have any stigmata of Cushing's syndrome (CS), except for central obesity, CS was excluded.

The adrenal masses did not exhibit contrast enhancement in the out phase of sequence, which was consistent with adenoma according to an experienced radiologist. The 24-h urine catecholamines findings based on HPLC were as follows: vanil-mandelic acid was $8.3 \mathrm{mg} / 24 \mathrm{~h}$, which was within the upper limit of normal (0-6 mg/24h); metanephrine was normal; normetanephrine was $1641 \mu \mathrm{g} / 24 \mathrm{~h}$, which was significantly higher than normal $(0-400 \mu \mathrm{g} / 24 \mathrm{~h})$. The patient did not have any pheochromocytoma-related symptoms, episodes of hypertension, palpitations, or flushing. Her adrenal imaging findings were not consistent with pheochromocytoma (Figures 1, 2 and 3).

MIBG scan was performed and it also was normal (Figures 4,5) Based on these findings, clozapine-induced pseudo pheochromocytoma was considered; a review of the literature showed that a few cases similar to the presented case have been reported $[12,13]$. Comprehensive investigations excluded all other causes of hypertension and elevated urinary catecholamines, and the final diagnosis was clozapine-induced pseudo pheochromocytoma.

The risks versus benefits of discontinuing clozapine were considered in collaboration with the treating specialist physicians, and discontinuation of clozapine was advised. Following psychiatric consultation, clozapine was withdrawn for 1 week, after which 24 -h urine catecholamines were normal: 5-hidroxyindolacetic acid: $4.6 \mathrm{mg} /$ 24h; metanephrine $119 \mu \mathrm{g} / 24 \mathrm{~h}$; normetanephrine: $283 \mu \mathrm{g} / 24 \mathrm{~h}$; vanilmandelic acid: $3.3 \mathrm{mg} / 24 \mathrm{~h}$. In addition, plasma renin activity [PRA] and the plasma aldosterone concentration [PAC] were $0.94 \mathrm{ng} / \mathrm{mL} / \mathrm{h}$ and $23 \mathrm{ng} / \mathrm{dl}$, respectively. The PAC to PRA ratio was 24.8 , but she did not have hypopotassemia. Due to the high PAC to PRA ratio $(>20)$ thesaline infusion test was performed. Following 4-h saline infusion $(500 \mathrm{~mL} / \mathrm{h})$ PAC decreased to $2 \mathrm{ng} / \mathrm{dL}(<5 \mathrm{ng} / \mathrm{dL})$, and primary hyperaldosteronism was therefore also excluded.

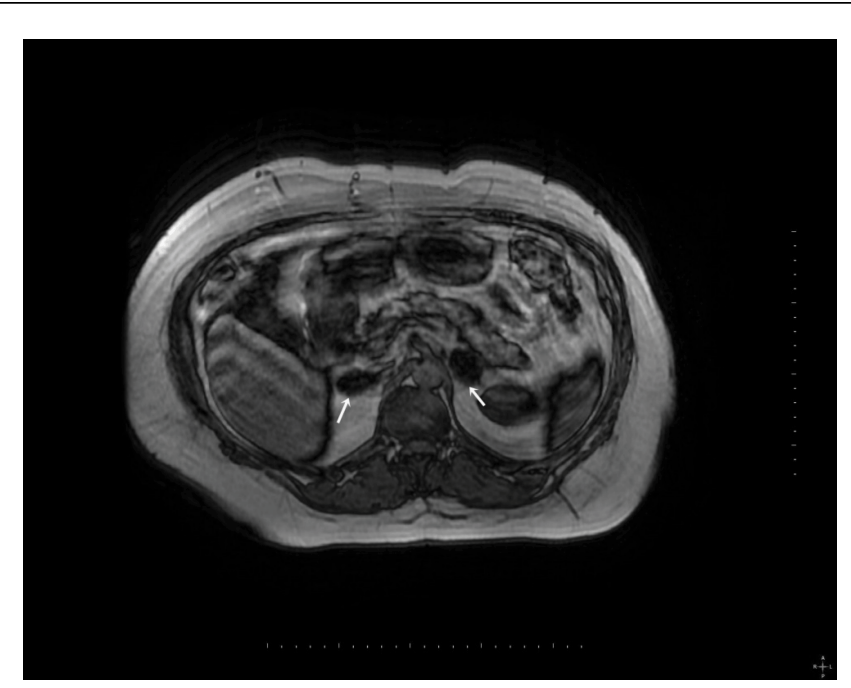

Figure 1: Out of phase sequence in the axial plane, both in the adrenal gland, nodular lesionis seen that goes off (white arrows).

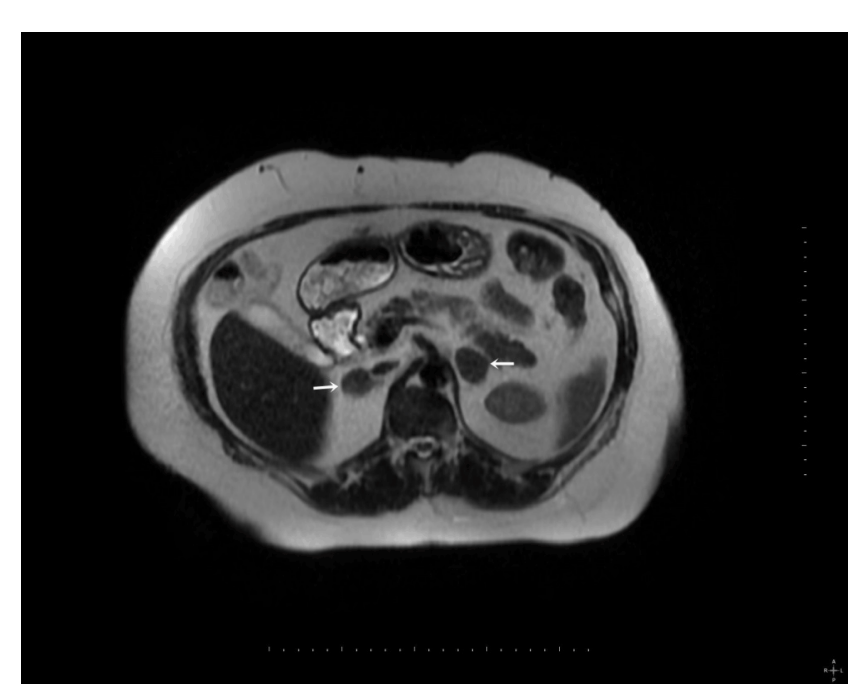

Figure 2: T2-weighted sequences in the axial plane, both hypo intense nodules in the adrenal glands are seen (white arrows).

\section{Discussion}

Clozapine is a tricyclic dibenzodiazepine derivate used for the treatment of schizophrenia. It's side effects include agranulocytosis and paradoxical hypertension with elevated 24-h catecholamines $[13,14]$. The neuropharmacological mechanisms of action of clozapine are complex, and include affinity for 5-HT2 receptors and a2adrenergic receptors in vitro [15]. Clozapine has been reported to cause an elevated plasma noradrenaline concentration, perhaps via inhibition of presynaptic reuptake mediated by a2-adrenergic receptors [16]. The other mechanism of clozapine-induced elevation in plasma NE levels is both increased spillover and decreased clearance or combination of them [17]. 
Citation: Arpaci D, Tocoglu GA, Gunduz Y, Korkmaz S, Tatli L, et al. (2014) A Case of Pseudopheochromocytoma Associated with Clozapine Therapy. J Psychiatry 17: 1000138. doi:10.4172/2378-5756.1000138

Page 3 of 4

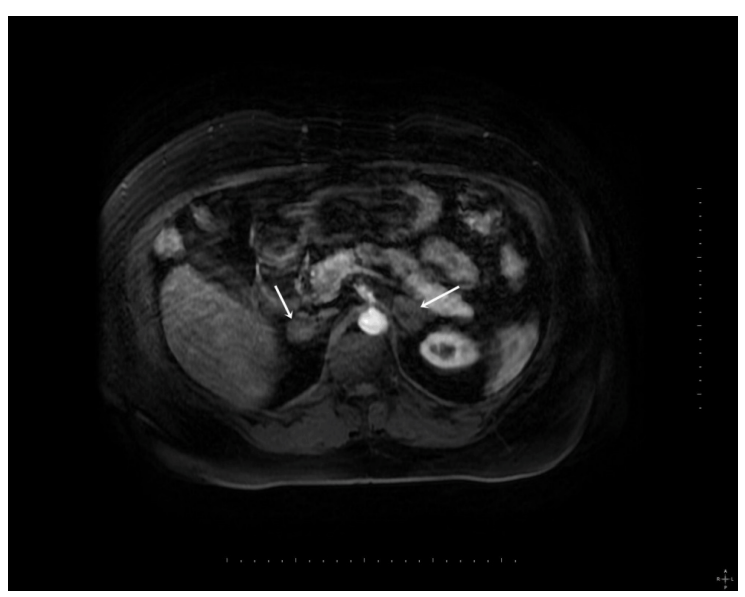

Figure 3: Axial T1-weighted fat-suppressed contrast-enhanced dynamic range plans related to the cross-section of nodular lesions in both adrenal glands contrast enhancement is not seen (white arrows).

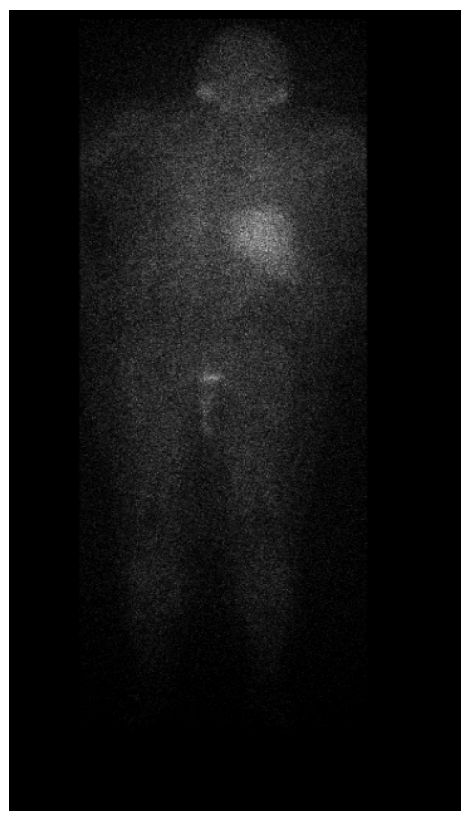

Figure 4: MIBG scans show normal findings (posterior Image).

The clinical effects of urine catecholamines remain uncertain. Some researchers have reported there are clinical effects [18,19], whereas others have reported there are no clinical effects, as in the presented patient [20]. Similar to the presented case, Li et al. [13] reported a 27year-old male with mimicking pheochromocytoma; their patient used clozapine to treat catatonic schizophrenia, and developed hypertension and elevated urinary catecholamines. Following withdrawal of clozapine their patient's blood pressure and urinary catecholamines returned to normal. Krentzet al. [14] reported 4 patients with pseudo pheochromocytoma syndrome that were treated with clozapine; following the withdrawal of clozapine the symptoms resolved and the urine catecholamine concentration returned to normal in all cases.

The association between clozapine treatment and onset of hypertension is controversial. In the literature, prevalence of hypertension associated with clozapine therapy was reported $4-16 \%$ in various studies $[21,22]$.

Given the potential for significant morbidity associated with pseudo pheochromocytoma syndrome, as undiagnosed cases are unlikely to receive clozapine treatment, we recommend early urinary catecholamine screening in all patients that develop hypertension or other typical symptoms following the initiation of clozapine treatment. The manufacturers of clozapine must develop international clinical guidelines for early diagnosis and management of pseudopheochromocytoma syndrome.

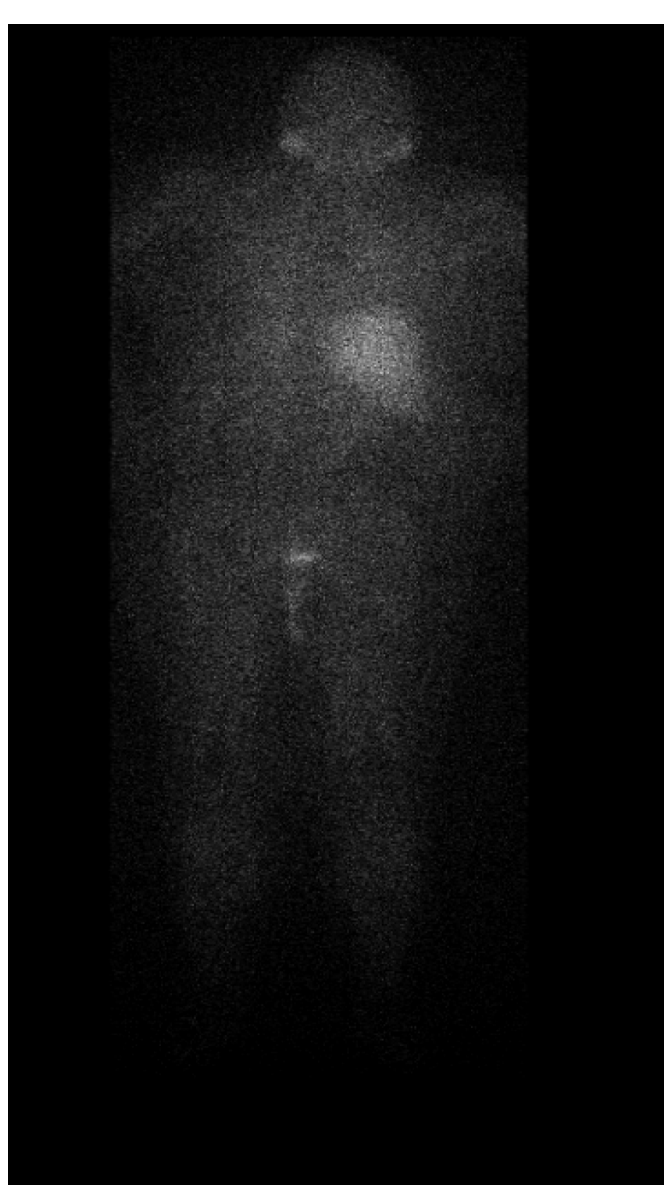

Figure 5: MIBG scans show normal findings (Anterior image).

\section{References}

1. Kannan S, Purysko A, Faiman C, Remer EM, Shah L, Bena J,et al. (2014) Biochemical and radiological relationships in patients with pheochromocytoma: lessons from a case control study. Clin Endocrinol (Oxf) 80: 790-796.

2. Song JH, Chaudhry FS, Mayo-Smith WW (2008) The incidentaladrenal mass on CT: prevalence of adrenal disease in 1,049 consecutiveadrenalmasses in patients with no known malignancy. AJR Am J Roentgenol 190: 1163-1168. 
3. Eisenhofer G, Tischler AS, de Krijger RR (2012) Diagnostic tests and biomarkers for pheochromocytoma and extra-adrenal paraganglioma: From routine laboratory methods to disease stratification. Endocr Pathol 23: 4-14.

4. Lenders JW, Pacak K, Walther MM, Linehan WM, Mannelli M, et al. (2002) Biochemical diagnosis of pheochromocytoma: which test is best? JAMA 287: 1427-1434.

5. Sawka AM, Jaeschke R, Singh RJ, Young WF (2003) A comparison of biochemical tests for pheochromocytoma: Measurement of fractionated plasma metanephrines compared with the combination of 24-hour urinary metanephrines and catecholamines. J Clin Endocrinol Metab 88: 553-558.

6. Jacques AE, Sahdev A, Sandrasagara M, Goldstein R, Berney D, et al. (2008) Adrenal phaeochromocytoma: Correlation of MRI appearances with histology and function. Eur Radiol 18: 2885-2892.

7. Sane T, Schalin-Jantti C, Raade M (2012) Is biochemical screening for pheochromocytoma in adrenal incidentalomas expressing low unenhanced attenuation on computed tomography necessary? J Clin Endocrinol Metab 97: 2077-2083.

8. Eisenhofer G, Goldstein DS, Walther MM, Friberg P, Lenders JW, et al. (2003) Biochemical diagnosis of pheochromocytoma: How to distinguish true- from false-positive test results. J Clin Endocrinol Metab 88: 2656-2666.

9. $\mathrm{Yu}$ R, Wei M (2010) False positive test results for pheochromocytoma from 2000 to 2008. Exp Clin Endocrinol Diabetes. 118: 577-585.

10. Brainard T (2014) Obstructive sleep apnea and tricyclic antideprssant use presenting as a pseudopheochromocytoma in an active duty sailor: a case report. Mil Med 179: 120-123.

11. Neary NM, King KS, Pacak K (2011) Drugs and pheochromocytoma-don't be fooled by every elevated metanephrine. N Engl J Med 364: 2268-2270.

12. Prasad SE, Kennedy HG (2003) Pseudophaeochromocytoma associated with clozapine treatment. Ir J Psych Med 20: 132-134.
13. Li JK, Yeung VT, Leung CM, Chow CC, Ko GT, et al. (1997) Clozapine: a mimicry of phaeochromocytoma. Aust N Z J Psyciatry 31: 889-891.

14. Krentz AJ, Mikhail S, Cantrell P, Hill GM (2001) Drug Points: Pseudophaeochromocytoma syndrome associated with clozapine. BMJ 322: 1213.

15. Eresbefsky L, Watanabe MD, Tran-Johnson TK (1989) Clozapine: an atypical antipsychotic agent. Clin Pharmacol 8: 691-709.

16. Davidson M, Kahn RS, Stern RG, Hirschowitz J, Apter S, et al. (1993) Treatment with clozapine and its effect on plasma homovanillic acid and norepinephrine concentrations in schizophrenia. Psychiatry Res 46: 151-163.

17. Elman I, Goldstein DS, Eisenhofer G, Folio J, Malthora AK, et al. (1999) Mechanism of peripheral noradrenergic stimulation by clozapine. Neuropsychopharmacology 20: 29-34.

18. Akinsola O, Ong K (2011) Pseudophaeochromocytoma associated with clozapine therapy: a case report.Afr J Psychiatry (Johannesbg) 14: 406-408.

19. Breier A, Buchanan RW, Waltrip RW 2nd, Listwak S, et al. (1994) The effect of clozapine on plasma norepinephrine: relationship to clinical efficacy. Neuropsychopharmacology 10: 1-7.

20. Ilias I, Pacak K (2004) Current approaches and recommended algorithm for the diagnostic localization of pheochromocytoma. Jclin Endocrinol Metab 89: 479-491.

21. Woo YS, Kim W, Chae JH, Yoon BH, Bahj WM (2009) Blood pressure changes during clozapine or olanzapine treatment in Korean schizophrenic patients. World J Biol Psychiatry 10: 420-425.

22. Lund BC, Perry PJ, Brooks JM, Arndt S (2001) Clozapine use in patients with schizophrenia and the risk of diabetes, hyperlipidemia, and hypertension: a claims-based approach. Arch Gen Psychiatry 58: 1172-1176. 